\title{
Eleatic Ontology in Aristotle: Introduction
}

DOI: $10.14746 /$ PEA.2021.1.1

\section{DAVID BRONSTEIN / University of New South Wales /}

\section{FABIÁN MIÉ / National University of Litoral /}

In the spirit of the Project Eleatic Ontology: Origin and Reception (EON), as described in the Introduction to Volume 1 by the General Editor and the driving force of this Project, Nicola Galgano (see his Presentation in the Brazilian journal Anais de Filosofia Clássica 14 (27), (2020)), we present here the Tome "Eleatic Ontology and Aristotle", devoted to Aristotle's reception of Parmenides and Eleaticism. This volume contains six original contributions (which we briefly summarize below) by outstanding scholars who provide in depth discussions of a wide range of topics, including: Aristotle's account of the relationship between materialist and Parmenidean monism; logical issues in his responses to Parmenides' eristic arguments; his solution to the problem of coming to be; and his responses to Zeno's paradoxes. This volume does not aim at uniformity or exhaustiveness in its treatment of Aristotle's reception of Eleaticism. Rather, our goal, as editors, was to collect new essays that consider a variety of issues in Aristotle's reaction to Parmenides and the Eleatic tradition. Each contribution advances the aim of the EON Project: to clarify the history and influence of Eleaticism. In particular, the essays in this volume help us better understand Aristotle's responses to Parmenides' and Zeno's challenges and the argumentative strategies and logical tools he employed to solve or avoid Eleatic problems. They also reveal important aspects of the ontology that Aristotle developed partly as a result of his confrontation with Eleaticism. The contributors address an array 
of philosophical, methodological, textual, doxographic, and historiographic issues and shed new light on difficult passages in both Aristotle and the Eleatics.

Given the nature and scope of the EON project, this volume is appropriately international, with scholars from seven countries on four continents serving as authors or editors. In the same spirit of internationalism we are pleased for these essays to be published in Peitho: Examina Antiqua and we offer our sincere thanks to the journal's editor Mikolaj Domaradzki and his colleagues at the Institute of Philosophy at Adam Mickiewcz University in Poland.

The contribution that opens this volume is devoted to an issue that is both characteristic of Eleaticism and controversial as to its origin: monism. In "Monism in Aristotle's Metaphysics I.3-5", Thomas Kjeller Johansen begins with the observation that Aristotle sees a significant degree of continuity between Parmenides and the materialist monists. He carefully considers what, for Aristotle, Parmenidian and materialist monism are and how they stand with respect to the theory of the four causes. Johansen's aim is to show that Aristotle's account of his predecessors is "a good deal more cogent and plausible than has been widely acknowledged". Central to Johansen's argument is the distinction between cause and principle. Aristotle's complaint about the materialist monists is not that they recognised only the material cause; it is that they made (a certain kind of) matter the principle of everything. This makes sense of the fact that Aristotle credits the materialists with a limited understanding of both efficient and material causation. Their deficiency was in failing to distinguish clearly among the four causes - or, put differently, their error was in holding that every cause is material (not that there is only the material cause). Johansen also argues that Aristotle sees Eleatic monism as a partial correction of materialist monism: according to Parmenides, if we define being correctly, we will see the impossibility not only of substantial change (as the materialists recognised) but also non-substantial change (or alteration). Parmenides' commitment to what Johansen calls 'formal monism' points the way forward to certain developments in Aristotle's thinking.

The next two contributions consider different aspects of Aristotle's discussion of Parmenides in Physics I. In "Aristotle's solution for Parmenides' inconclusive argument in Physics I.3", Lucas Angioni uses the technical concept of eristic argument in the Topics and Sophistical Refutations as the basis for a new interpretation of Aristotle's account of, and solution to, Parmenides' argument for monism in Physics I.3 (Ph. 186a22-b14). According to this technical concept, an argument is eristic if it has a false premise or is 'inconclusive'. Aristotle asserts that Parmenides' argument has both flaws. He is clear about the false premise: it is the claim that things are said to be in only one way, when in fact they are said to be in many ways $(P h .186 a 24-25)$. He is much less clear about the argument's inconclusiveness. Clarifying this aspect of Aristotle's solution (lusis) is the task Angioni sets for himself. He proceeds step by step through the notoriously difficult passage ( $P h .186 a 25-b 12)$ in which we are asked to substitute 'white' for 'being' in an argument that allegedly runs parallel to Parmenides' argument for monism. Angioni pays particularly close attention to key Greek terms and expressions, especially ö $\varepsilon \varepsilon \rho$

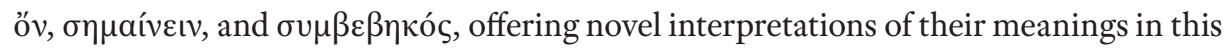


passage. By focusing in addition on the concept of 'being one in account', Angioni is able to argue that Aristotle's solution rests on the distinction between what it is to be white and that which has the property of being white. What Parmenides missed, according to Aristotle on this interpretation, is the difference between being and the subject of which being is predicated. Once this distinction is made, the inconclusiveness of Parmenides' argument is made clear and monism is avoided.

In Physics I.8 (Ph. 191a23-24), Aristotle announces that the Eleatic argument against change can be solved. The argument, in Aristotle's words, is that "nothing comes to be or passes away, because what comes to be must do so either from what is or from what is not, and neither is possible" ( $P h$. 191a27-31). Takashi Oki (in "Aristotle's Refutation of the Eleatic Argument in Physics I.8") offers a careful analysis of this chapter and sheds light on Aristotle's difficult anti-Eleatic argument. Oki argues that, for Aristotle, the Eleatics denied the possibility of coming to be from what is qua what is and from what is not qua what is not. Aristotle agrees with this. However, he argues that they failed to see a third possibility, which Oki understand as follows: something comes to be from what is qua what is not - for example, the musical man comes to be from the man qua un-musical. This interpretation of Aristotle's solution allows Oki to argue that the sense in which something comes to be from what is is the same as the sense in which it comes to be from what is not: again, something comes to be from what is qua what is not. It also allows him to make good sense of several key claims in $P h$. I.7-8, for example, that the starting-point of coming to be is privation ( $P h .191 \mathrm{~b} 15)$, that what comes to be is always composite ( $P h$. 19ob11), and that something comes to be 'accidentally' from what is ( $P h .191 \mathrm{~b} 18)$ and 'accidentally' from what is not $(P h$. 191b14-15). Oki closes his paper by putting $P h$. I.8 in the context of $P h$. I as a whole: he suggests that the discussion of Eleaticism in I.8 is a way of making the three principles (form, subject, and privation) reached in I.7 more knowable to us, as required by the methodology laid out in $P h$. I.1.

The final three contributions to this volume focus on Zeno of Elea, Parmenides' most important follower. Zeno is well known in the Ancient World as the inventor of dialectic and the author of several paradoxes that worried not only ancient authors but also modern philosophers and mathematicians, such as Leibniz and Bertrand Russell, as well as writers and poets, such as Paul Valery and Jorge Luis Borges. Barbara Sattler's essay “What about Plurality? Aristotle's discussion of Zeno's Paradoxes" focuses on Zeno's paradoxes of plurality. She notes that we have evidence of several Zenonian paradoxes on three topics - motion, place (topos), and plurality - along with the single paradox of the falling millet seed. Aristotle and his ancient commentators are our main sources for all of these, and Sattler begins with an overview of the paradoxes of motion, topos, and the falling millet seed, all of which appear in the Physics and thus in the context of Aristotle's attempt to found the science of nature. Sattler aims to explain why Aristotle pays so little attention to the paradoxes of plurality as compared to his treatment of the other paradoxes. She focuses on a passage in Metaphysics III that contains his only discussion of Zeno on plurality and she compares his perfunctory treatment of the issue to the fuller discussions we find in Plato and Simplicius, arguing that, for Aristotle, the problem of plurality 
belongs to metaphysics, not natural science, and that a plurality of individual substances is a starting-point and not something he needs to argue for or derive.

In “Aristotle, Eleaticism, and Zeno's Grains of Millet”, Marcelo D. Boeri scrutinizes Aristotle's discussion in Physics VII of Zeno's 'millet seed' paradox: since a single grain of millet makes no sound upon falling, neither do a thousand grains. Boeri argues against the view that this is a sorites problem. Rather, he argues that the paradox casts doubt on Aristotle's theory of mathematical proportions, especially his theory of the proportions that hold between the moving power and the object moved. This explains the context in which Aristotle discusses the paradox and the connection he draws between it and two other cases: the stone being worn away by a drop of water and the hauled ship. In this way, Boeri shows how Aristotle's discussion of the paradox is deeply anchored in his theory of continuous magnitudes and mathematical proportions in Physics VI and VII. Boeri's contribution also considers the relationship between Aristotelian and Newtonian physics and reflects on the purpose and value of Aristotle's engagement with Eleaticism in the development of his science of nature.

The importance of Zeno for the historical picture of Eleaticism can safely be measured by Aristotle's attempts at solving his puzzles. Michel Crubellier's contribution (“An Ontology for the In-Between of Motion: Aristotle's Reaction to Zeno's Arguments") focuses on Aristotle's reports and criticisms of Zeno's four puzzles in Physics VI.9 (Ph. 239b5-240a15): the Dichotomy, the Achilles, the Arrow, and the Stadium. Crubellier argues that Aristotle's solutions apply the results of his ontological analysis of motion in Books V-VI. A significant contribution of this paper is a novel interpretation of the Stadium puzzle and Aristotle's solution, an interpretation based on a new reconstruction of the Greek text informed by a careful study of the manuscripts. In addition to offering a close reading of Physics VI.9, Crubellier's wide-ranging paper puts Aristotle's engagement with Zeno in the context of the Physics as a whole, examining such questions as whether Zeno should be understood as having evinced an interest in ontology, what the nature of Zeno's method was, whether it influenced Aristotle's own method in the final books of the Physics (Crubellier argues that it did: both methods are dialectical, informed by a priori reasoning, and proceed at a high level of abstraction), what the relationship is, for Aristotle, between locomotion and change in general, and how to understand the analogies he draws between magnitude, motion, and time. Crubellier closes with a discussion of two key issues in Aristotle's ontological analysis of change (which were omitted in Aristotle's discussion of change in Book I): (1) the 'in-between' and (2) the 'before' and 'after'. 
DAVID BRONSTEIN

/University of New South Wales, Australia /

d.bronstein@unsw.edu.au

FABIÁN MIÉ

/ National University of Litoral, Argentina / fabian.mie@conicet.gov.ar

\section{Eleatic Ontology in Aristotle: Introduction}

The introduction summarizes the six new papers collected in Volume 1, Tome 5: Eleatic Ontology and Aristotle. The papers take a fresh look at virtually every aspect of Aristotle's engagement with Eleaticism. They are particularly concerned with Aristotle's responses to Parmenidean monism, the Eleatic rejection of change, and Zeno's paradoxes. The contributions also focus on the ways in which Aristotle developed several of his own theories in metaphysics and natural science partly in reaction to Eleatic puzzles and arguments.

Eleaticism, Aristotle, Parmenides, Zeno, Ontology, Monism, Motion, Time, Magnitude, Infinity 
